УДК 796.035

DOI https://doi.org/10.26661/2663-5925-2020-1-02

\title{
ФІЗИЧНА ПІДГОТОВЛЕНІСТЬ СТУДЕНТІВ АГРАРНИХ СПЕЦІАЛЬНОСТЕЙ ВИЩИХ НАВЧАЛЬНИХ ЗАКЛАДІВ
}

\author{
Вовк I. B. \\ завідувач кафедри фізичного виховання, \\ старший викладач кафедри фізичного виховання \\ Львівський національний аграрний університет \\ вул. В. Великого, 1, Дубляни, Львівська область, Україна \\ orcid.org/0000-0001-6075-6094 \\ igorvasylovych@gmail.com \\ Мадяр-Фазекаш Е. О. \\ старший викладач кафедри фізичного виховання \\ Ужггородський національний університет \\ вул. Івана Франка, 6, Ужгород, Україна \\ orcid.org/0000-0002-8310-0423 \\ madyarfazekash@gmail.com
}

Ключові слова: фізичне виховання, фізична підготовленість, студенти аграрних спеціальностей, диференціація, контроль.
У статті проаналізовано сучасні тенденції розвитку системи фізичного виховання для підвищення рівня фізичної підготовленості студентів аграрних спеціальностей вищих навчальних закладів. Установлено перспективні напрями вдосконалення процесу фізичного виховання. Мета дослідження полягає у проведенні аналізу й оцінці фізичної підготовленості студентів аграрних спеціальностей у вищих навчальних закладах. Матеріали $i$ методи. Дослідження проводилось на кафедрі фізичного виховання Львівського національного аграрного університету у 2019-2020 навчальному році. У дослідженні взяли участь 70 студентів I курсу, які були віднесені до основної медичної групи. Для визначення рівня розвитку фізичних якостей ми обрали загальноприйняті нормативи державної системи тестування. Результати. За соціологічним опитуванням преважна частина студентів має інтерес до фізичної культури: $62,1 \%$ - середній ступінь зацікавленості в заняттях, тільки $54,2 \%$ студентів займались у спортивних секціях, дещо більша кількість студентів (58,4\%), які продовжують заняття у спортивних секціях під час навчання в університеті. На думку опитаних студентів, фізичне виховання у виші повинне зміцнювати здоров'я (45,2\%). Під час проведення тестування фізичних якостей студентів перших курсів на почату та в кінці навчального року ми встановили практично «синхронний» рівень розвитку фізичних якостей. Результати студентів першого курсу аграрних спеціальностей характеризуються статистичною стабільністю (p > 0,05), тоді як рівень їхніх резервних можливостей не дозволяє забезпечити високу працездатність студентської молоді. Висновки. За результатами аналізу наукової та методичної літератури можна констатувати широкий спектр наукових досліджень із даної проблематики. Як показує практика, результати наукового пошуку досі не повною мірою сприяють підвищенню фізичної підготовленості студентської молоді. Так, ми встановили незадовільний рівень фізичної підготовленості у студентіваграрників, особливо низьким рівнем розвитку характеризуються такі фізичні якості, як: човниковий біг (спритність) $(2,14 \pm 0,98$ бали) та нахил тулуба з положення сидячи, см (гнучкість) $(\mathrm{p}<0,05)$. 


\title{
PHYSICAL PREPAREDNESS OF STUDENTS OF AGRICULTURAL SPECIALTIES OF HIGHER EDUCATIONAL INSTITUTIONS
}

\author{
Vovk I. V. \\ Head of the Department of Physical Education, \\ Assistant Professor at the Department of Physical Education \\ Lviv National Agrarian University \\ V. Velykoho str., 1, Dublyany, Lviv region, Ukraine \\ orcid.org/0000-0001-6075-6094 \\ igorvasylovych@gmail.com \\ Madyar-Fazekash E. O. \\ Assistant Professor at the Department of Physical Education \\ Uzhhorod National University \\ Ivana Franka str., 6, Uzhhorod, Ukraine \\ orcid.org/0000-0002-8310-0423 \\ madyar.fazekash@gmail.com
}

Key words: physical education, physical readiness, students of agricultural specialties, differentiation, control.
The article analyzes the current trends in the development of the physical education system to increase the level of physical fitness of students in agricultural specialties of higher educational institutions. Perspective directions of improvement of the process of physical education are established. The purpose of the study is to analyze and assess the physical fitness of students of agricultural specialties in higher education. Materials and methods. The study was conducted at the Department of Physical Education of Lviv National Agrarian University in 2019-2020. The study involved 70 first-year students, who were assigned to the main medical group. To determine the level of development of physical qualities, we chose the generally accepted standards of the state testing system. Results. According to the poll, the majority of students are interested in physical culture: $62,1 \%$ - the average degree of interest in classes, only $54,2 \%$ of students were engaged in sports sections, a slightly larger number of students $(58,4 \%)$ who continue to engage in sports sections while studying at the university. According to the surveyed students, physical education in higher education should: strengthen health $-45,2 \%$. During the testing of physical qualities of first-year students at the beginning and the end of the school year, we established a virtually "synchronous" level of development of physical qualities. The results of firstyear students of agricultural specialties are characterized by statistical stability $(p>0,05)$, although the level of their reserve capacity does not allow to ensure high efficiency of student youth. Conclusions. According to the results of the analysis of scientific and methodical literature allows to state about a wide range of scientific researches on the given problems. As practice shows, the results of scientific research are still not fully conducive to improving the physical fitness of student youth. Thus, we found an unsatisfactory level of physical fitness in agricultural students, especially low level of development is characterized by such physical qualities as: shuttle running (agility) $(2,14 \pm 0,98$ points $)$ and the inclination of the torso from a sitting position, $\mathrm{cm}$ (flexibility) $(\mathrm{p}<0,05)$. 
Постановка проблеми. Основною проблемою сьогодення є здоров'я студентів аграрних спеціальностей та студентської молоді була і залишається актуальною. Це пов'язано з тим, що за останні роки прослідковується чітка тенденція до погіршення стану іï здоров'я та фізичного розвитку. За останні роки було зазначено загальне збільшення кількості серцево-судинних захворювань, порушення функціональних резервів організму, порушення постави, наявність різних вад опорно-рухового апарату, зниження рівня фізичної підготовленості [8]. Це все супроводжується інтенсивністю навчального процесу, зниженням рухової активності студентів, зокрема й через зменшення кількості академічних годин із фізичного виховання, проведення секційних занять за бажання студентів, а то й цілковитої відмови від цієї дисципліни в багатьох вищих навчальних закладах. У формуванні здоров'я студентської молоді недооцінюють роль фізичної культури, а також основна iï маса хронічно не задовольняе своєї біологічної потреби в руховій активності. Натепер не розроблені соціально-економічні стимули, які здатні формувати активне ставлення до власного здоров'я, а також відсутня мода на здоров'я і фізичну досконалість, культуру здоров'я. Оскільки саме фізична підготовленість студентської молоді $є$ одним 3 основних критеріїв здоров'я, а у практиці фізичного виховання студентів закладу вищої освіти - основним критерієм його ефективності, зокрема розвитку фізичних якостей, формування рухових умінь, зміцнення здоров'я $[5-7 ; 13 ; 14]$.

Основною ланкою здоров'я, високої працездатності та життєздатності, базою, завдяки якій відбувається вся рухова діяльність людини, є рівень фізичної підготовленості. У зв'язку із цим зміцнення здоров'я й підвищення рівня фізичної підготовленості студентів на основі ефективних, науково обгрунтованих програм із фізичного виховання має першочергове соціально-економічне значення (О. Вацеба, С. Козіброцький, 2003, 2005 рр.; Т. Бойчук, 2007 р.; Ю. Круцевич, 2008 р.; Г. Грибан, 2012 р.; С. Присяжнюк, 2013 р.; інші).

Фізичне виховання у вищих навчальних закладах $є$ важливою ланкою і практично єдиною можливістю запобігти фізичній деградації студенської молоді [10].

Фізична підготовленість - результат фізичної активності студентів, їхній інтегральний показник, тому що під час виконання фізичних вправ у взаємозв'язок вступають практично всі органи і системи організму [3].

Аналіз останніх досліджень і публікацій. Науковці (А. Лапутін, 2001 р.; Е. Вільчковський, 2012 р.; Р. Раєвський, 2007 р.; О. Куц, 2012 р., інші) довели, що розвиток рухових якостей сприяє розв'язанню соціально важливих завдань: усебічному та гармонійному розвиткові особистості, досягненню високої стійкості організму до несприятливих екологічних умов та підвищенню адаптивних властивостей організму.

Водночас інші автори (В. Заціорський, 1991 р.; О. Касарда, 2008 р.; Л. Сергієнко, 2008 р.; В. Лищевська, 2009 р.; Р. Бака, 2010 р.; Л. Волков, 2011 р.) зазначають, що процес розвитку рухових якостей передусім потребує добре налагодженого педагогічного контролю.

Науковці (L. Bomirska, 2000 p.; T. Lisicki, 2002 р.; С. Воронін, 2009 р.; О. Фанигіна, 2005 р.) довели, що спортивна спрямованість викликає у студентської молоді позитивні емоції й інтерес до занять, сприяє підвищенню їхньої рухової підготовленості, зростанню спортивно-технічної майстерності.

За останні роки значну кількість опублікованих робіт присвячено особливостям диференціації й індивідуалізації процесу фізичного виховання Б. Леко (2003 р.); М. Воробйов, Т. Круцевич (2005 p.); Н. Москаленко, Д. Воротніцева (2008 р.); Л. Сергієнко (2010 р.).

Автори пропонують різні диференційовані підходи до організації процесу фізичного виховання: 3 урахуванням мотиваційних, особистісних і когнітивних компонентів (О. Рибалка, 2010 р.); психофізичних особливостей студентів (А. Лукавенко, 2013 р.); соматотипів та конституції тілобудови (В. Гладенкова 2009 р.); Г. Сдинак, 2011 р.); рівня фізичного стану (О. Малімон, 1998 р.; Л. Долженко, 2007 р.; М. Попічєв, 2011 р.).

Пошуки способів підвищення рівня фізичного розвитку та фізичної підготовленості студентів розглянуто в роботах Г. Грибана, 2009-2013 pp.; А. Магльованого, 1997, 1998, 2009-2011 рр.; Т. Лози, 2012 р.; О. Кузнєцової, 2006-2013 рр.; С. Присяжнюка, 2002-2008 рр., інших науковців.

Питання визначення рівня фізичної підготовленості студентів аграрних спеціальностей у закладі вищої освіти (далі - ЗВО) є актуальним. Це необхідно для оптимального фізичного навантаження, адекватного вибору методики в системі занять фізичною культурою, щоби скласти адекватні програми оздоровчих занять для аграріїв у ЗВО.

Мета дослідження полягає у проведенні аналізу й оцінці фізичної підготовленості студентів аграрних спеціальностей у вищих навчальних закладах.

Методи дослідження. Теоретичні (аналіз і узагальнення наукової літератури), емпіричні методи (опитування), тестування (для визначення рівня фізичної підготовленості), методи математичної статистики. 
Дослідження проводилось на кафедрі фізичного виховання Львівського національного аграрного університету у 2019-2020 н. р. У дослідженні взяли участь 70 студентів I курсу, які були віднесені до основної медичної групи. Для визначення рівня розвитку фізичних якостей ми обрали загальноприйняті нормативи державної системи тестування.

Виклад основного матеріалу дослідження. На початку року нами було проведено соціологічне опитування для визначення ставлення студентів аграрних спеціальностей до занять iз фізичного виховання і спорту. Вивчили їхню думку про цінність занять фізичними вправами порівняно з іншими засобами впливу на фізичний стан (табл. 1).

Таблиця 1

Оцінка ставлення студентів аграрних спеціальностей до фізичного виховання і спорту

\begin{tabular}{|l|c|}
\hline \multicolumn{1}{|c|}{ Запитання } & $\%$ \\
\hline Ваш інтерес до занять із фізичної культури: & \\
- дуже високий; & $7,3 \pm 1,6$ \\
- високий; & $26,0 \pm 2,5$ \\
- середній; & $62,1 \pm 3,2$ \\
- низький; & $2,4 \pm 0,9$ \\
- відсунній. & $2,2 \pm 0,8$ \\
\hline Чи займались Ви у спортивних секціях? & \\
- Так; & $54,2 \pm 2,7$ \\
- ні. & $45,8 \pm 2,7$ \\
\hline Чи продовжуєте Ви зараз займатись & \\
у спортивній секції? & $58,4 \pm 2,8$ \\
- Так; & $34,6 \pm 2,8$ \\
- ні. & \\
\hline Яку мету Ви ставите на заняттях & \\
із фізичного виховання у ЗВО? & $45,2 \pm 2,6$ \\
- Зміцнення здоров'я; & $32,6 \pm 2,7$ \\
- підвищення фізичного розвитку & \\
і фізичної підготовки; & $9,4 \pm 1,8$ \\
- формування рухових умінь і навичок; & $5,2 \pm 1,6$ \\
- сприяння розумовому розвитку; & $4,1 \pm 1,2$ \\
- формування потреб і можливостей & \\
щодо регулярних занять фізичною & \\
кульурою; & $2,1 \pm 0,8$ \\
- розвиток моральних, вольових & \\
і естетичних якостей; & $1,4 \pm 0,3$ \\
- інша. & \\
\hline Які показники фізичного стану & \\
для Вас є найважливішими? & $10,2 \pm 1,9$ \\
- Фізичний розвиток; & $15,4 \pm 2,0$ \\
- стан здоров'я; & $4,7 \pm 1,2$ \\
- сила, витривалість; & $0,3 \pm 0,7$ \\
- розумовий розвиток; & $69,4 \pm 2,7$ \\
\hline - не турбуюсь. & \\
\hline
\end{tabular}

Аналіз отриманих результатів засвідчив, що преважна частина студентів аграрних спеціальностей мають інтерес до фізичної культури: $62,1 \%$ - середній ступінь зацікавленості в заняттях,
$26 \%$ - високий, 7,3\% - дуже високий. Тільки $54,2 \%$ студентів займались у спортивних секціях. Дещо зросла кількість студентів $(58,4 \%)$, які й далі займаються у спортивних секціях під час навчання в університеті. На думку опитаних студентів, фізичне виховання у виші повинне: зміцнювати здоров' ' $-45,2 \%$, підвищувати рівень фізичного розвитку - $32,6 \%$, формувати рухові вміння та навички $-9,4 \%$, сприяти розумовому розвитку $-5,2 \%$, формувати потребу і мотивацію до регулярних занять $-4,1 \%$.

Отримані нами результати соціологічного дослідження характеризують ставлення студентів аграрних спеціальностей до фізичної культури і суттєво не відрізняються від даних, опублікованих останнім часом іншими авторами $[4 ; 9 ; 11 ; 12]$.

Під час проведення тестування фізичних якостей студентів аграрних спеціальностей на початку та в кінці навчального року ми встановили практично «синхронний» рівень розвитку фізичних якостей.

Аналіз результатів з бігу на 60 та 100 м свідчить про тенденцію до підвищення результату в кінці навчального року $(8,70 \pm 0,48 \mathrm{c})$, за шкалою оцінювання $-3,33 \pm 1,01$ бали, $14,24 \pm 0,56 \mathrm{c}$, $2,90 \pm 1,09$ бали (табл. 2).

Аналіз результатів тестування студентів із човникового бігу свідчить про незадовільний рівень розвитку спритності, оскільки на початку року середній показник становить 9,98 $\pm 0,40$ с, у кінці року результат майже аналогічний $-9,95 \pm 0,46 \mathrm{c}$. Такий незадовільний рівень розвитку спритності пояснюється значним впливом адаптаційних процесів організму студентів до змін навчання у виші.

Результати стрибка в довжину 3 місця свідчать про задовільний рівень швидкісно-силової підготовленості студентів аграрних спеціальностей. Студенти на початку року навчання продемонстрували результат $223,37 \pm 10,94$ см, у кінці навчального року $-226,33 \pm 11,77$.

Силова витривалість студентів характеризується задовільним рівнем розвитку. У тесті піднімання тулуба студенти на початку року показали результат $40,73 \pm 6,38$ рази, у кінці навчального року він був дещо вищий $(42,51 \pm 4,92), 2,96 \pm$ 0,77 бали. Результати тесту характеризуються аналогічною тенденцією, як і результати студентів у стрибку в довжину з місця. Наші дані збігаються 3 даними $[1 ; 2]$ про незадовільний рівень розвитку сили. Результат у тесті на гнучкість на початку року становить $11,40 \pm 3,66 \mathrm{~cm}$, у кінці спостерігається незадовільний рівень розвитку силових показників $(10,00 \pm 3,93 \mathrm{~cm})$.

За результатами проведеного тестування серед студентів аграрних спеціальностей можна дати загальну характеристику оцінці рівня розвитку 
Таблиця 2

Рівень фізичної підготовленості студентів аграрних спеціальностей $(\mathrm{n}=70)$

\begin{tabular}{|c|c|c|c|c|c|}
\hline \multirow{3}{*}{ Контрольні випробування } & \multicolumn{5}{|c|}{ Статистичні характеристики } \\
\hline & \multicolumn{2}{|c|}{ На початку року } & \multicolumn{2}{|c|}{ У кінці року } & \multirow[b]{2}{*}{$P$} \\
\hline & $\mathbf{M} \pm \mathbf{S D}$ & Бал \pm SD & $\mathbf{M} \pm \mathbf{S D}$ & Бал \pm SD & \\
\hline Біг на 60 м, с & $8,90 \pm 0,41$ & $2,84 \pm 0,80$ & $8,70 \pm 0,48$ & $3,33 \pm 1,01$ & $<0,05$ \\
\hline Біг на 100 м, с & $14,39 \pm 0,90$ & $2,79 \pm 1,31$ & $14,24 \pm 0,56$ & $2,90 \pm 1,09$ & $>0,05$ \\
\hline Стрибок у довжину з місця, см & $223,37 \pm 10,94$ & $2,56 \pm 0,73$ & $226,33 \pm 11,77$ & $2,81 \pm 0,85$ & $>0,05$ \\
\hline Човниковий біг 4 × 9, с & $9,98 \pm 0,41$ & $2,10 \pm 0,72$ & $9,95 \pm 0,46$ & $2,14 \pm 0,98$ & $>0,05$ \\
\hline Прес, к-сть разів & $40,73 \pm 6,38$ & $2,66 \pm 1,01$ & $42,51 \pm 4,92$ & $2,96 \pm 0,77$ & $>0,05$ \\
\hline Нахил тулуба & $11,40 \pm 3,66$ & $2,77 \pm 1,21$ & $10,00 \pm 3,93$ & $2,40 \pm 1,24$ & $<0$ \\
\hline
\end{tabular}

фізичної підготовленості. Основна частина (70\%) студентів характеризуються нижчим від середнього рівнем фізичної підготовленості, у 5,7\% студентів виявлено низький рівень підготовленості, лише $24,3 \%$ - 3 вищим за середній рівнем фізичної підготовленості.

Варто звернути увагу на відповідність шкільних вимог вимогам вишів із фізичного виховання i переглянути навчальні програми з даної дисципліни.

Висновки. За результатами аналізу наукової та методичної літератури можна зазначити велику кількість наукових досліджень із даної проблематики. Як показує практика, результати наукового пошуку досі не повною мірою сприяють підвищенню рівня фізичної підготовленості студентів аграрних спеціальностей. Так, ми встановили незадовільний рівень фізичної підготовленості у студентів-аграрників, особливо низьким рівнем розвитку характеризуються такі фізичні якості, як: човниковий біг (спритність) $(2,14 \pm 0,98$ бали) та нахил тулуба з положення сидячи (гнучкість) $(\mathrm{p}<0,05)$.

Перспектива подальших досліджень полягатиме в корекції процесу фізичного виховання студентів аграрних спеціальностей шляхом реалізації диференційованого підходу.

\section{ЛІТЕРАТУРА}

1. Боляк Н. Сучасні підходи до проблеми вдосконалення процесу фізичного виховання студентської молоді. Слобожанський науково-спортивний вісник. Харків : ХДАФК, 2009. № 2. С. 22-25.

2. Воронин С. Личностно ориентированная физическая подготовка студентов непрофильных вузов. Теория и практика физической культуры. 2009. № 7. С. 59-64.

3. Грибан Г. Особливості фізичної підготовленості студентів вищих навчальних закладів України. Bicник Чернігівського національного педагогічного університету. Серія «Педагогічні науки. Фізичне виховання та спорт». 2014. Вип. 118. С. 88-93.

4. Гринько В. Ставлення студентів до фізичного виховання і здорового способу життя та їх самооцінка рівня фізичної підготовленості. Слобожанський науково-спортивний вісник. Харків : ХДАФК, 2015. № 1 (45). С. 55-59.

5. Зеленюк О. Рейтингова система як засіб оцінки ефективності фізичного виховання студентів-медиків. Роль фізичної культури в здоровому способі життя : матеріали I Всеукраїнської науково-практичної конференції. Львів, 1993. Ч. І. С. 7-8.

6. Круцевич С. Диференційований підхід у фізичному вихованні студентської молоді. Оптимізація процесу фізичного виховання. Тернопіль, 1997. С. 30-31.

7. Куц А. Модельные показатели физического развития и физической подготовленности детей Центральной Украины. Киев : Искра, 1994. 253 с.

8. Мозговий О., Донченко I. Загальна характеристика здоров’я студентів ВНЗ. Вісник Запорізького національного університету : збірник наукових статей. Фізичне виховання та спорт. Запоріжжя : Запорізький національний університет, 2012. № 2 (8). С. 92-97.

9. Мунтян В. Мотиваційно-ціннісне ставлення студентів до навчання, фізичного виховання і здорового способу життя. Науковий часопис Наиіонального педагогічного університету імені М.П. Драгоманова. Серія 15. Київ : Вид-во НПУ імені М.П. Драгоманова, 2014. № 3 К (45). С. 182-188.

10. Петрина Р., Стадник В., Окопний А. Оцінювання показників фізичної підготовленості студентів ВНЗ. Молода спортивна наука Украӥни : електронний збірник наукових праць з галузі фізичної культури та спорту. Львів, 2013. Т. 2. С. 212-216.

11. Петрица П. Ставлення студентів до фізичної культури і спорту у процесі їх фізичного виховання. Молода спортивна наука Украӥни : збірник наукових праць з галузі фізичного виховання, спорту і здоров’я людини / за заг. ред. Є. Приступи. Львів, 2015. Вип. 19. Т. 2. С. 212-216. 
12. Плачинда Т. Ставлення студентів до фізичної культури і спорту у процесі їх фізичного виховання. Психолого-педагогічні проблеми сільської школи. 2007. № 23. С. 38-42.

13. Решетников Н. Как же оценить физическую подготовленность. Теория и практика физической культуры. 1990. № 5. С. 41-43.

14. Рябцев В., Токар Д. Комплексная оценка физической подготовленности студентов по результатам контрольных упражнений. Теория и практика физической культуры. 1998. № 3. С. 11.

\section{REFERENCES}

1. Boliak NL. (2009) Suchasni pidkhody do problemy vdoskonalennia protsesu fizychnoho vykhovannia studentskoi molodi [Modern approaches to the problem of improving the process of physical education of student youth]. Slobozhanskyi naukovo-sportyvnyi visnyk. - Kh. - № 2. - S. $22-25$.

2. Voronin S. (2009) Lichnostno orientirovannaya fizicheskaya pidgotovka studentov neprofilnyih vuzov [Personally oriented physical training of students of non-core universities]. Teoriya i praktika fizicheskoy kulturyi. - № 7. - S. 59-64

3. Hryban H..P. (2014) Osoblyvosti fizychnoi pidhotovlenosti studentiv vyshchykh navchalnykh zakladiv Ukrainy [Features of physical fitness of students of higher educational institutions of Ukraine]. Visnyk Chernihivskoho natsionalnoho pedahohichnoho universytetu im. T.H. Shevchenka: zb. nauk. pr. - Chernihiv: ChNPU. - Vyp. 118. - S. 88-93

4. Hrynko V.M. (2015) Stavlennia studentiv do fizychnoho vykhovannia i zdorovoho sposobu zhyttia ta yikh samootsinka rivnia fizychnoi pidhotovlenosti [Attitudes of students to physical education and a healthy lifestyle and their self-assessment of physical fitness]. Slobozhanskyi naukovo-sportyvnyi visnyk. Kharkiv : KhDAFK. - № 1 (45). - S. 55-59.

5. Zeleniuk O.V. (1993) Reitynhova systema yak zasib otsinky efektyvnosti fizychnoho vykhovannia studentiv-medykiv [Rating system as a means of assessing the effectiveness of physical education of medical students]. I Vseukrainska naukovo-praktychna konferentsiia "Rol fizychnoi kultury $v$ zdorovomu sposobi zhyttia". Ch. I. - Lviv, - S. 7-8.

6. Krutsevych S.H. (1997) Dyferentsiiovanyi pidkhid u fizychnomu vykhovanni studentskoi molodi [Differentiated approach in physical education of student youth]. Optymizatsiia protsesu fizychnoho vykhovannia. - Ternopil. - S. 30-31.

7. Kuts A.S. (1994) Modelnyie pokazateli fizicheskogo razvitiya i fizicheskoy podgotovlennosti detey Tsentralnoy Ukrainyi [Model indicators of physical development and physical fitness of children in Central Ukraine]. - K.: Iskra. - $253 \mathrm{~s}$

8. Mozgoviy O.I, Donchenko I.S. (2012) Zagalna harakteristika zdorov'ya studentIv VNZ [General characteristics of the health of university students]. VIsnik ZaporIzkogo natsIonalnogo unIversitetu. № $2(8)-$ S. 92-97

9. Muntian V.S. (2014) Motyvatsiino-tsinnisne stavlennia studentiv do navchannia, fizychnoho vykhovannia i zdorovoho sposobu zhyttia [Motivational and value attitude of students to education, physical education and a healthy lifestyle]. Naukovo-pedahohichni problemy fizychnoi kultury. - K.: v-vo NPU im. M.P. Drahomanova. - Vypusk 3 K (45) - S. 182-188.

10. Petryna R, Stadnyk V, Okopnyi A. (2013) Otsiniuvannia pokaznykiv fizychnoi pidhotovlenosti studentiv VNZ [Evaluation of indicators of physical fitness of university students]. Moloda sportyvna nauka Ukrainy. - T. 2. - S. 212-216

11. Petrytsa P. (2015) Stavlennia studentiv do fizychnoi kultury i sportu u protsesi yikh fizychnoho vykhovannia [Attitudes of students to physical culture and sports in the process of their physical education]. Moloda sportyvna nauka Ukrainy: zb. nauk. pr. z haluzi fizychnoho vykhovannia, sportu i zdorovia liudyny / za zah. red. Yevhena Prystupy. - L. - Vyp. 19. - T. 2. - S. 212-216.

12. Plachynda T. (2007) Stavlennia studentiv do fizychnoi kultury i sportu u protsesi yikh fizychnoho vykhovannia [Attitudes of students to physical culture and sports in the process of their physical education]. Psykholoho-pedahohichni problemy silskoi shkoly. - № 23. - S. 38-42.

13. Reshetnikov N.V. (1990) Kak zhe otsenit fizicheskuyu podgotovlennost [How to assess physical fitness]. Teoriya i praktika fizicheskoy kulturyi. - № 5. - S. 41-43.

14. Ryabtsev V.M., Tokar D.S. (1998) Kompleksnaya otsenka fizicheskoy podgotovlennosti studentov po rezultatam kontrolnyih uprazhneniy [Comprehensive assessment of students' physical fitness based on the results of control exercises]. Teoriya i praktika fizicheskoy kulturyi. - № 3. - S. 11. 